\title{
Potent Neutralizing Humanized Antibody With Topical Therapeutic Potential Against HPV18-Related Cervical Cancer
}

OPEN ACCESS

Edited by

Olivera J. Finn,

University of Pittsburgh, United States

Reviewed by:

Ji Wang,

Sun Yat-Sen University, China

Rupsa Basu,

Helaina Inc., United States

*Correspondence:

Zhiwei Wu

wzhw@nju.edu.cn

Xilin Wu

xilinwu@nju.edu.cn

Ying Hong

hongying@nju.edu.cn

${ }^{\dagger}$ These authors have contributed equally to this work

Specialty section:

This article was submitted to Vaccines and Molecular Therapeutics, a section of the journal

Frontiers in Immunology

Received: 09 March 2021

Accepted: 31 May 2021

Published: 24 June 2021

Citation:

Huang B, Zhu L, Wei H, Shi H, Zhang $D$, Yuan $H$, Luan L, Zheng $N$, Xu S, Nawaz W, Hong Y, Wu X and

Wu Z (2021) Potent Neutralizing

Humanized Antibody With Topical Therapeutic Potential Against HPV18Related Cervical Cancer.

Front. Immunol. 12:678318. doi: 10.3389/fimmu.2021.678318

\begin{abstract}
Bilian Huang ${ }^{1 \dagger}$, Linjing Zhu ${ }^{2 \dagger}$, Hongxia Wei ${ }^{3}$, Haixia Shi ${ }^{4}$, Doudou Zhang ${ }^{2}$, Huanyun Yuan ${ }^{2}$, Linlin Luan ${ }^{2}$, Nan Zheng ${ }^{1}$, Shijie $\mathrm{Xu}^{2}$, Waqas Nawaz ${ }^{1}$, Ying Hong ${ }^{5 *}$, Xilin $W u^{1,2 *}$ and Zhiwei $W u^{1,6,7,8 *}$
\end{abstract}

${ }^{1}$ Center for Public Health Research, Medical School, Nanjing University, Nanjing, China, ${ }^{2}$ Department of Antibody, Abrev Biotechnology Co., Ltd., Nanjing, China, ${ }^{3}$ Department of Infection, Nanjing Hospital Affiliated to Naniing University of Chinese Medicine, Nanjing, China, ${ }^{4}$ Department of Antibody, Y-Clone Medical Science Co. Ltd., Suzhou, China, ${ }^{5}$ Obstetrics and Gynecology Department, Nanjing Drum Tower Hospital, Affiliated Hospital of Nanjing University Medical School, Nanjing, China, ${ }^{6}$ School of Life Sciences, Ningxia University, Yinchuan, China, ${ }^{7}$ Jiangsu Key Laboratory of Molecular Medicine, Medical School, Nanjing University, Nanjing, China, ${ }^{8}$ State Key Laboratory of Analytical Chemistry for Life Science, Nanjing University, Nanjing, China

Cervical cancer caused by human papillomavirus (HPV) infections is the fourth most common cancer in women worldwide. Current prophylactic HPV vaccines have achieved promising success in preventing HPV infection. However, still 570,000 new cases were reported in 2018. The current primary treatment for the patient with cervical cancer is either surgery or chemoradiotherapy. Cervical cancer still lacks standard medical therapy. HPV18 induced cervical cancer has the worst prognosis and high mortality compared to other HPV infections. The development of HPV18 related with cervical malignancy requires the persistent infection of cervical-vaginal epithelium by HPV18 subtype, which can take years to transform the epithelium. This period of repeated infection provides a window for therapeutic intervention. Neutralizing antibodies formulated as topical agents that inhibit HPV18 infection should reduce the chance of cervical malignancy. We previously demonstrated that potent neutralizing anti-sera against HPV18 infection were induced by HPV18 viral like particle (VLP) generated in mammalian cells. We, therefore, isolated two potent neutralizing antibodies, $2 \mathrm{~A} 12$ and $8 \mathrm{H} 4$, from over 3,810 hybridomas prepared from mice immunized with HPV18 VLP. 2A12 and 8H4 exhibited excellent potency, with $50 \%$ virus-inhibitory concentrations $\left({ } \mathrm{C}_{50}\right)$ of 0.4 and $0.9 \mathrm{ng} / \mathrm{ml}$, respectively. Furthermore, $2 \mathrm{~A} 12$ and $8 \mathrm{H} 4$ recognized distinct and non-overlapping quaternary epitopes and bound specifically with HPV18. Humanized 2A12 (Hu2A12) retained comparable neutralizing activity against HPV18 infection in various acidic $\mathrm{pH}$ settings and in hydrogel formulation with $\mathrm{IC}_{50}$ values of 0.04 to $0.77 \mathrm{ng} / \mathrm{ml}$, indicating that Hu2A12 will be a promising candidate for clinical development as a topical vaginal biopharmaceutical agent against HPV18 infection.

Keywords: HPV18, cervical cancer, neutralizing antibodies, topical agents, humanized antibody 


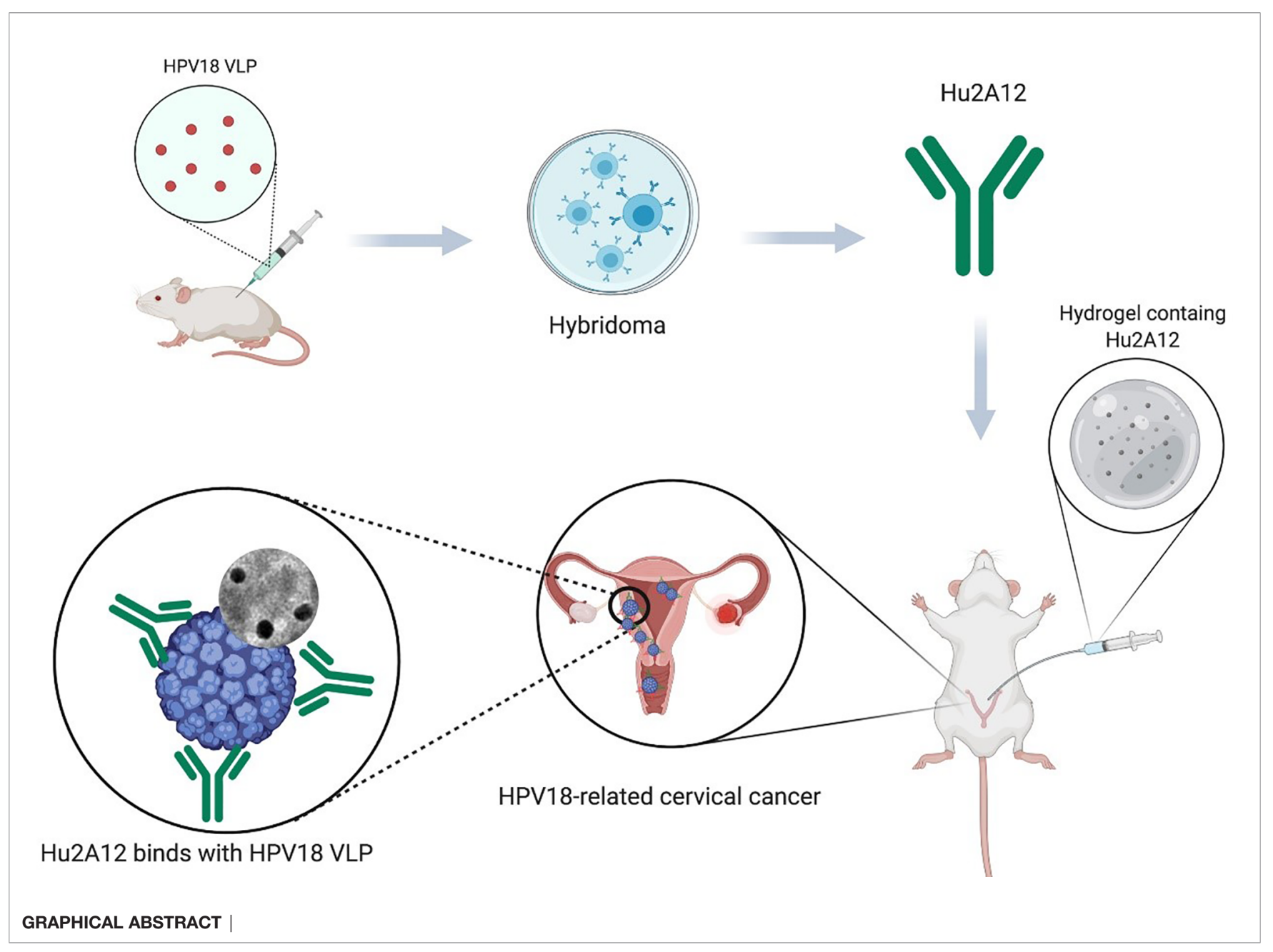

\section{HIGHLIGHTS}

1. Two neutralizing antibodies against HPV18 with the highest potency were isolated from immunized mice.

2. The humanized antibody, Hu2A12, exhibits ultrahigh potency against HPV18 infection with $\mathrm{IC}_{50}$ value of 0.04 $\mathrm{ng} / \mathrm{ml}$.

3. Hu2A12 retains comparable neutralizing activity in various acidic $\mathrm{pH}$ settings and in hydrogel formulation.

4. Hu2A12 will be a promising candidate as a topical vaginal biopharmaceutical agent against HPV18 infection.

\section{INTRODUCTION}

Cervical cancer is the fourth most common tumor diagnosed in women worldwide (1). Persistent infections caused by high-risk Human papillomaviruses (HPV), such as 16, 18, 31, 33, 35, 39, $45,51,52,56,58,59$ and 68 are considered to be the main cause for the development of cervical cancer precursors, known as cervical intraepithelial neoplasia ( $\mathrm{CIN} \mathrm{1,2,} \mathrm{and} \mathrm{3),} \mathrm{and} \mathrm{invasive}$ cervical cancer $(2,3)$.

Current prophylactic HPV vaccines have achieved remarkable success in preventing HPV infection $(4,5)$. However, a large number of women still failed to receive prophylactic HPV vaccines due to the high cost, failed to respond to the vaccination and other factors. In 2018, 570,000 new cases and 311,000 related deaths were reported globally, indicating effective treatment was urgently needed (6). Surgical or chemoradiotherapeutic regimens are the current primary treatment options for patients with cervical cancer. Specific medical treatment for HPV infection remains elusive (7).

Persistent HPV infection in the basal layer of the cervical epithelium is the main risk factor in the development of the premalignant conditions of cervical intraepithelial neoplasia or adenocarcinoma in situ. Without treatment, the transition from dysplasia to invasive carcinoma may take years to decades to develop in most women.

Current research on topical therapies for the treatment of HPV or CIN have promising results, signified by the randomized trials of immune-modulating (imiquimod), anti-proliferative (5fluorouracil), and anti-viral (cidofovir) therapies (8-10). However, none of them has profound clinical evidence to be 
recommended as a treatment for CIN 2-3 and surgery remains the standard of care (11). Cidofovir is an approved antiviral drug for the treatment of cytomegalovirus (CMV) retinitis in HIV patients. Clinical studies of cidofovir gel as a topical therapy had shown promising results for clearance of HPV or CIN. However, serious side effects were recently reported in the use of cidofovir in the treatment of HPV infection (12). All these indicate that topical anti-viral therapy is promising; however, antibody based topical therapy for HPV or CIN has not been reported yet.

The use of neutralizing antibodies with high potency and low toxicity have been widely applied to treat viral infections caused by a respiratory syncytial virus, cytomegalovirus, human immunodeficiency virus, Ebola virus and influenza virus (13, 14). The discovery and development of virus-neutralizing monoclonal antibodies can be a promising approach to eliminate HPV persistent infection and prevent the subsequent transition of invasive carcinoma.

After HPV16, HPV18 infection is the second most carcinogenic HPV genotype in a large percentage (approximately 10\%), and highly enriched in adeno/adenosquamous and adenocarcinoma in situ compared to lower grades of diagnosis (2, 15, 16). HPV18 causes cervical cancer with the worst prognosis as compared with other types of HPV $(17,18)$. Two neutralizing antibodies against HPV18 were previously developed for diagnostic kit for HPV-18 (19). To our knowledge, no neutralizing antibodies with high potency have been developed for HPV 18 treatment. We previously demonstrated that high potent neutralizing anti-sera against HPV18 infection could be induced by our HPV18 viral like particle (VLP) generated in the mammalian cell. In this study, two potent neutralizing antibodies, $2 \mathrm{~A} 12$ and $8 \mathrm{H} 4$, were isolated from more than 3,810 hybridomas prepared from mice immunized with HPV18 VLP (20). 2A12 and 8H4 exhibited high potency, with $\mathrm{IC}_{50}$ of 0.4 and $0.9 \mathrm{ng} / \mathrm{ml}$, respectively. Furthermore, 2A12 and 8H4 recognized distinct and nonoverlapping quaternary epitopes and exhibited specific binding with HPV18. Humanized 2A12 (Hu2A12) retains comparable neutralizing activity against HPV18 infection in various acidic $\mathrm{pH}$ conditions and hydrogel with the $\mathrm{IC}_{50}$ of 0.04 to $0.7 \mathrm{ng} / \mathrm{ml}$, indicating that $\mathrm{Hu} 2 \mathrm{~A} 12$ will be a promising candidate for clinical development as topical vaginal biopharmaceutical agents in hydrogel against HPV18 infection.

\section{METHODS AND MATERIALS}

\section{Production of HPV18 VLP and HPV18 Pseudovirus}

HPV18 VLP and pseudovirus were prepared using the plasmid of p18sheLL (Addgene, 37321) and the co-transfection of p18shell and pGMCMV-luc (Yeasen Biotech) as a reporter gene, respectively, as we previously described (20), with some modifications. In brief, the plasmids were mixed with PEI (Polysciences, MW25000, 23966-1) at a 1:3 ratio and then transfected into 293 TT cells. About $48 \mathrm{~h}$ post-transfection, cells were harvested and washed with DPBS twice. After centrifugation, the cell pellet was resuspended in $0.5 \%$ Triton
X-100 and $25 \mathrm{mM}$ ammonium sulfate. The cell lysate was then incubated at $37^{\circ} \mathrm{C}$ for $24 \mathrm{~h}$. The matured lysate on ice was incubated for $15 \mathrm{~min}$ with the final concentration of $850 \mathrm{mM}$ $\mathrm{NaCl}$. After centrifugation, the supernatant was transferred for OptiPrep (D1156, Sigma-Aldrich, St. Louis, Missouri, USA) gradient purification at $40,000 \mathrm{rpm}$ for $4.75 \mathrm{~h}$. Different fractions were collected for verification.

\section{Immunization of Mice}

Five 8-week-old female Balb/c mice (M1 M5) were immunized by three subcutaneous injections, at two weeks interval, of 25-50 $\mu \mathrm{g}$ HPV 18 VLP emulsified with Freund's adjuvant (Sigma, F5881 \& F5506). Sera were collected one week after the third immunization and were used to further analysis. An intraperitoneal injection of HPV18 VLP without adjuvant was performed as the booster immunization before hybridoma.

\section{Enzyme-Linked Immunosorbent Assay}

To measure the serum titer or antibody against HPV18 VLP, ELISA plates (Corning, 9018) were coated with $0.5 \mu \mathrm{g} / \mathrm{ml}$ purified HPV18 VLP at $4^{\circ} \mathrm{C}$ overnight, then blocked in $2 \%$ bovine serum albumin-PBST. Sera were diluted in $2 \%$ bovine serum albumin-PBST. Diluted sera or hybridoma culture supernatant was added and then incubated at $37^{\circ} \mathrm{C}$ for $1.5 \mathrm{~h}$. After a wash with PBST, anti-mouse IgG HRP conjugated antibodies (Jackson ImmunoResearch115-035-003) were added

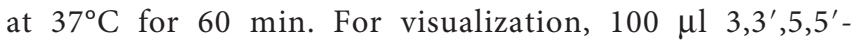
Tetramethylbenzidine (TMB, Sigma) substrate was added and incubated at room temperature for $10 \mathrm{~min}$, and stopped with $50 \mu \mathrm{l} 1 \mathrm{M} \mathrm{HCl}$ per well. Optical densities were determined at 450 nm using Infinite 200 (Tecan).

\section{Preparation of Hybridomas and Identification of Candidate Clones}

Mice were sacrificed 3 days after booster immunization. Splenocytes were isolated, fused with $\mathrm{Sp} 2 / 0$ cells (ATCC) in a 1:2 ratio using Electro Cell Manipulator (BTX Harvard Apparatus, ECM 2001) as described $(21,22)$. Fused cells were cultured in hypoxanthine aminopterin thymidine (HAT, Sigma, H0262) medium in multiple 96-well plates, and supernatants were tested after 7 days in culture. The supernatants of the individual hybridoma clones were screened for HPV18 VLP specific antibodies by ELISA. The selected positive hybridoma supernatants were further analyzed using neutralization assay. All the candidate clones were subcloned at least twice by limiting dilution.

\section{HPV Neutralization Assay}

The pseudovirus-based neutralization assay was performed to evaluate the activity of antibodies inhibiting HPV infection, following the previously reported method (20) with slight modifications. Briefly, 10,000 293TT cells were seeded per well overnight in a 96-well cell culture microplate in growth media. Serial dilutions of antibodies or anti-sera were incubated with HPV pseudovirus at $37^{\circ} \mathrm{C}$ for $1 \mathrm{~h}$. Then, the mixture was transferred to the 96-well plates and incubated with cells at $37^{\circ} \mathrm{C}$ for $48 \mathrm{~h}$. After that, the supernatant was removed, and 
substrate (Promega Bright-Glo luciferase Assay System, E2650) was added to the samples to read Fluorescence intensity. The $\mathrm{IC}_{50}$ value was calculated based on the previously published standard algorithm (23).

\section{Western Blot}

About 200 ng HPV VLPs were mixed with $5 \times$ SDS-PAGE nonreduce sample buffer $(250 \mathrm{mM}$ Tris- $\mathrm{HCl}, \mathrm{pH}$ 6.8, 10\% SDS, $0.05 \%$ bromophenol blue, $20 \%$ glycerol) and boiled for $5 \mathrm{~min}$. For reduced HPV18 VLP, 5x SDS-PAGE reduce sample buffer (250 mM Tris-HCl, pH 6.8, 500 mM DTT, 10\% SDS, $0.05 \%$ bromophenol blue, $20 \%$ glycerol) was added. The proteins were separated by electrophoresis on 10\% SDS-PAGE gels, and the gels were then transferred onto a $0.45-\mu \mathrm{m}$ PVDF membrane. (Bio-Rad, 10485196). The membrane was soaked in blocking buffer (2\% BSA in PBST) at room temperature for $1 \mathrm{~h}$, and then incubated with hybridoma supernatant or anti-sera at room temperature for $2 \mathrm{~h}$, followed by three times of washing. A secondary antibody of anti-mouse IgG with an IRDye $800 \mathrm{CW}$ (Li-COR, 925-32210) was used and the immunoblots were visualized using an Odyssey Infrared Imaging System (LI-COR).

\section{Identification of Antibody Isotypes}

Mouse antibody isotypes were determined using mouse monoclonal antibody subtype identification Kit (Cellway-Lab, C030215), following the manufacturer's protocol. In brief, a sample of evaluated antibody was added in the ELISA plate. After incubation and washing, the secondary antibodies specific for IgG1, IgG2a, IgG2b, IgG3, IgA and IgM were added. The high optical density $(450 \mathrm{~nm})$ suggests the right antibody isotype or subtype.

\section{Flow Cytometric Analysis}

293TT cells were transfected with the plasmid of p18sheLL to express VLP. Some $48 \mathrm{~h}$ later, cells were collected, fixed in formalin for $20 \mathrm{~min}$, treated with $0.2 \%$ TritonX-100 for $10 \mathrm{~min}$ and then blocked in PBS with 1\% FBS (PBSF) for $2 \mathrm{~h}$. 2A12 and $8 \mathrm{H} 4$ were added and incubated for $1 \mathrm{~h}$ at room temperature. After washing twice with PBSF, binding antibodies were detected by an incubation at $4^{\circ} \mathrm{C}$ for $30 \mathrm{~min}$ with Alexa Fluor ${ }^{\circledR}$ 488-AffiniPure Goat Anti-Mouse IgG $(\mathrm{H}+\mathrm{L})$ (Jackson Immunoresearch, 115545-146). After washing, the cells were resuspended in $500 \mu \mathrm{l} \mathrm{PBSF}$ and analyzed using ACEA NovoCyte TM (Agilent Biosciences) Nontransfected 293TT cells were served as a negative control.

\section{Electron Microscopy and Immunogold Labeling}

Immunoelectron microscopy (Immune-EM) of the HPV virion was performed as described previously (24). For staining, $10 \mu \mathrm{l}$ HPV18 VLP was adsorbed on copper grids for $10 \mathrm{~min}$. Afterward, the grids were blotted dry with filter paper and transferred facing down onto a drop of $2 \%$ BSA-PBS.10 min later, the grid floated on droplets including primary antibody for $1 \mathrm{~h}$ at room temperature, followed by the grids being rinsed on three drops of PBS in the same way. Then, an anti-mouse secondary antibody conjugated to $10 \mathrm{~nm}$ gold particles (Sigma G7652-.4ML) diluted 1:500 in 2\% BSA-PBS was applied for $30 \mathrm{~min}$. Following washing with PBS, the grid was negatively contrasted with $2 \%$ phosphotungstic acid (Macklin P829844-5g) by incubating at room temperature for 4 min. Finally, samples were dry and observed using transmission electron microscopy (JEM-2100).

\section{Sequencing and Analysis of Mouse Ig Genes}

Some $1 * 10^{7}$ hybridoma cells were collected and washed with PBS, then lysed with Trizol (Ambion, 15596018) to extract total RNA according to the manufacturer's instructions. RNA was reverse transcribed to cDNA using PrimeScript ${ }^{\mathrm{TM}}$ II 1 st Strand cDNA Synthesis Kit (Takara, 6210A). The resulting cDNA was used as the template for amplifying heavy and light-chain variable gene using the Mouse Ig-Primer Set (Merck Millipore, 6983). The gene was then sequenced, adopting standard methods (25). The International ImMunoGeneTics Information System (IMGT) (http://imgt.cines.fr) was used to analyze the variable domain VH/VL. To confirm the sequences, the vectors of pCDNA3.4-VH-CH and pCDNA3.4-VL-CL containing the gene of VH and VL were constructed and co-transfected 293TT cells. The cell supernatant was then detected by ELISA as described above.

\section{Antibody Humanization}

The mouse IgG humanization was achieved by complementarity determining regions (CDR) grafting $(26,27)$. The sequence of $2 \mathrm{~A} 12 \mathrm{VH} / \mathrm{VL}$ were blasted against human heavy and light variable chain by using searches of IMGT/Domain Gap Align comprehensive database of Ig. Combined with the sequence analysis of the Molecular Operating Environment (MOE) and its three-dimensional structure from molecular modeling, critical diversity residues in the framework of $2 \mathrm{~A} 12$ were identified. Then CDR grafted with humanized heavy and light chain were constructed by partly replacing critical diversity residues with human original residues. The combined expression of diverse designed humanized heavy and light chains resulted in multiple different pairings of humanized antibodies molecules. Pairing with the highest affinity and neutralizing activity were selected.

\section{Quantification of Mouse IgG}

The mouse IgG in serum or in hybridoma supernatant was quantified using double antibody sandwich ELISA. Briefly, the anti-mouse IgG (Sigma, M0659, Fab specific, F $\left(\mathrm{ab}^{\prime}\right)_{2}$ fragment antibody produced in goat) was coated. After blocking, series gradient diluted sample and mouse IgG standards $(0-100 \mathrm{ng} / \mathrm{ml})$ were added as primary antibodies, while anti-mouse IgG (Fc specific)-peroxidase antibody (Sigma, A2554) was used as a secondary antibody. The linear regression curve of the mouse IgG standards was drawn, and the $\mathrm{OD}_{450}$ value was brought into the equation to calculate the mouse IgG concentration of each sample.

\section{Biolayer Interferometry}

The affinity of HPV18 specific antibodies was determined using the Octet RED96 instrument (Sartorius). Amine reactive biosensor (AR2G, 18-5092) was used to immobilize the HPV18 VLP. AR2G biosensors were activated for $7 \mathrm{~min}$ with EDC 
(400mM)/NHS (100 mM), and then immersed $15 \mathrm{~min}$ in HPV18 VLP which was diluted in pH $5.010 \mathrm{mM}$ sodium acetate buffer. Transfer the sensor to ethanolamine for $7 \mathrm{~min}$ and then to $0.02 \%$ PBST for affinity assay. The kinetics assays were performed with a shaking speed of 1,000 rpm. Association with HPV18 VLP specific antibodies was measured for $4 \mathrm{~min}$ and dissociation in $0.02 \%$ PBST for $4 \mathrm{~min}$. The affinity analysis was performed using a fast 1:1 binding model and the Data analysis software 8.0 (Sartorius).

The epitope-binding assay was performed with AR2G biosensor following the manufacturer's protocol 'in-tandem assay'. The immobilization of antigen was performed as above described, and then associated the first antibody $(20 \mu \mathrm{g} / \mathrm{ml})$ for $400 \mathrm{~s}$ following with the baseline step with $30 \mathrm{~s}$ immersion in $0.02 \%$ PBST. Accordingly, the sensors were immersed for 400 s with a second antibody at $20 \mu \mathrm{g} / \mathrm{ml}$. Graph Pad was used to illustrate the time-response course of two antibodies binding to HPV18 VLP.

\section{Preparation of Antibody Hydrogel and In Vitro Release Kinetics}

To generate a hydrogel formulation contained antibodies, $\mathrm{Hu} 2 \mathrm{~A} 12$ was diluted in sterile $\mathrm{ddH}_{2} \mathrm{O}$ at a final concentration of $1 \mathrm{mg} / \mathrm{ml}$. Subsequently, $70 \mathrm{mg}$ Hydroxyethyl cellulose (HEC, Macklin, H810926) was added to the $1 \mathrm{ml}$ above antibody solution containing $\mathrm{Hu} 2 \mathrm{~A} 12$, which shook for $1 \mathrm{~h}$ at room temperature, accordingly, 7\% (wt/vol) HEC hydrogel containing antibodies was prepared.

For drug release studies, 7\% HEC containing Hu2A12 labeled with FITC (hu2A12-FITC) was prepared (28-30). Transwell (NEST, 725301) inserts perforated with ten 22-G needle were used as filters. About $300 \mu \mathrm{l}$ hydrogel was applied onto the insert membrane, followed by a gentle addition of $0.5 \mathrm{ml}$ PBS. Some $1.5 \mathrm{ml}$ PBS was applied to the lower chamber. About $100 \mu \mathrm{l}$ aliquots in the lower chamber were transferred to a black 96-well plate (Greiner, 655076) and made up by $100 \mu \mathrm{l}$ fresh PBS at the indicated time. Hu2A12 labeled by FITC was quantified by fluorescence at $485 \mathrm{~nm}$ excitation wavelength and $525 \mathrm{~nm}$ emission wavelength using a fluorescence multi-well plate reader (Molecular Devices M3). In vitro cumulative percentage release was calculated using the formula as below:

Relative amount of drug in released solution

$=\mathrm{OD}_{525}$ of sample withdrawn $* 20$

Cumulative percentage release (\%)

relative amount of drug in released solution at time $t+$ cumulative drug withdrawn previous to $t$ relative total amount of drug

\section{Neutralization Activity Under Acidic Conditions}

To apply the antibodies under acidic conditions, we firstly detected the neutralization activity of Hu2A12 in the media of $\mathrm{pH} 4,5,6$, and 7 . The complete DMEM media was adjusted with acidic acid to $\mathrm{pH} 4,5,6$, and 7. The neutralization assay was similar to the 'HPV neutralization assay' as described above with some changes as follow. Both antibodies and pseudovirus were diluted in corresponding acidic media. Four hours after adding the mixture of antibodies and pseudovirus in the seeded cells, the acidic media was replaced with conventional media to avoid the cells from acid toxicity. Some $48 \mathrm{~h}$ later, neutralizing activity was measured.

The Hu2A12 released from vaginal hydrogel was evaluated for neutralization activity. Sodium acetate buffer ( $\mathrm{pH}$ 5.0) was applied as an antibody released buffer to mimic the acidic environment of the vagina. About 1.5 fold volume of acidic buffer was added to the antibody hydrogel, making the gel disintegrated completely in $37^{\circ} \mathrm{C}$, which was maintained for $72 \mathrm{~h}$. At 24 and $72 \mathrm{~h}$, the released antibodies were sampled for neutralization assay.

\section{In Vivo Retention of Antibody Hydrogel in a Mouse Model}

Hu2A12 was labeled with far infrared dye $\mathrm{YF}^{\circledR} 750$ SE (US EVERBRIGHT INC, YS0056) (named Hu2A12-750). Nine female nude mice (18-22 g, Qing Long Shan Animal Breeding Grounds, Nanjing, China) were divided into three groups. Three mice in Group 1 were intra-vaginally treated with $50 \mu \mathrm{g} \mathrm{Hu} 2 \mathrm{~A} 12-750$ hydrogel, while three mice in Group 2 were injected with $50 \mu \mathrm{g}$ liquid Hu2A12-750 in the same way. The remaining three mice were used as negative control. Far infrared images were observed at $15 \mathrm{~min}, 4 \mathrm{~h}, 8 \mathrm{~h}, 24 \mathrm{~h}$ and $48 \mathrm{~h}$ with a small animal imaging system (NightOWL LB $983 \mathrm{NC100)}$ ) at Ex: 740 nm/Em:780 nm. Images were captured by the CCD camera embedded in the imaging system and analyzed using Indigo imaging software Ver. A 01.19.01.

\section{Statistics}

Graphs were generated by GraphPad Prism 5.01 software or OriginPro 8.5 software (Origin-Lab). One- or 2-way ANOVA was performed for group comparisons. $\mathrm{P}<0.05$ was considered statistically significant with data shown as mean \pm SEM or mean $\pm \mathrm{SD}$ or median + range.

\section{RESULTS}

\section{Generation of Anti-HPV18VLP mAbs}

$\mathrm{Balb} / \mathrm{c}$ mice were immunized with HPV18 VLP generated in 293TT cells as depicted in Figure 1A. High titer (ranging 1.0-9.8 $\times 10^{6}$ dilution) anti-sera from five immunized mice specific for HPV18 VLP protein was achieved after the third immunization (Figure 1B). M1 mouse with the highest anti-serum titer was sacrificed for the hybridoma production. 1223 hybridoma supernatants, including 3,810 clones, were evaluated for the binding with HPV18 VLP protein, and, among them, 106 positive supernatants were scored as high positive $\left(\mathrm{OD}_{450} \mathrm{~nm}>1.0\right)$ for HPV18 VLP binding, yielding an overall hit rate of $8.7 \%$ (Figure 1C). Specially, hybridomas with high antigen binding were advanced for further subclone. Supernatants of seven mAbs were screened for preliminary neutralization assessment against HPV18 infection. Two monoclonal antibodies (named as 2A12 and $8 \mathrm{H} 4$ ) showed $100 \%$ inhibition against HPV 18 infection 

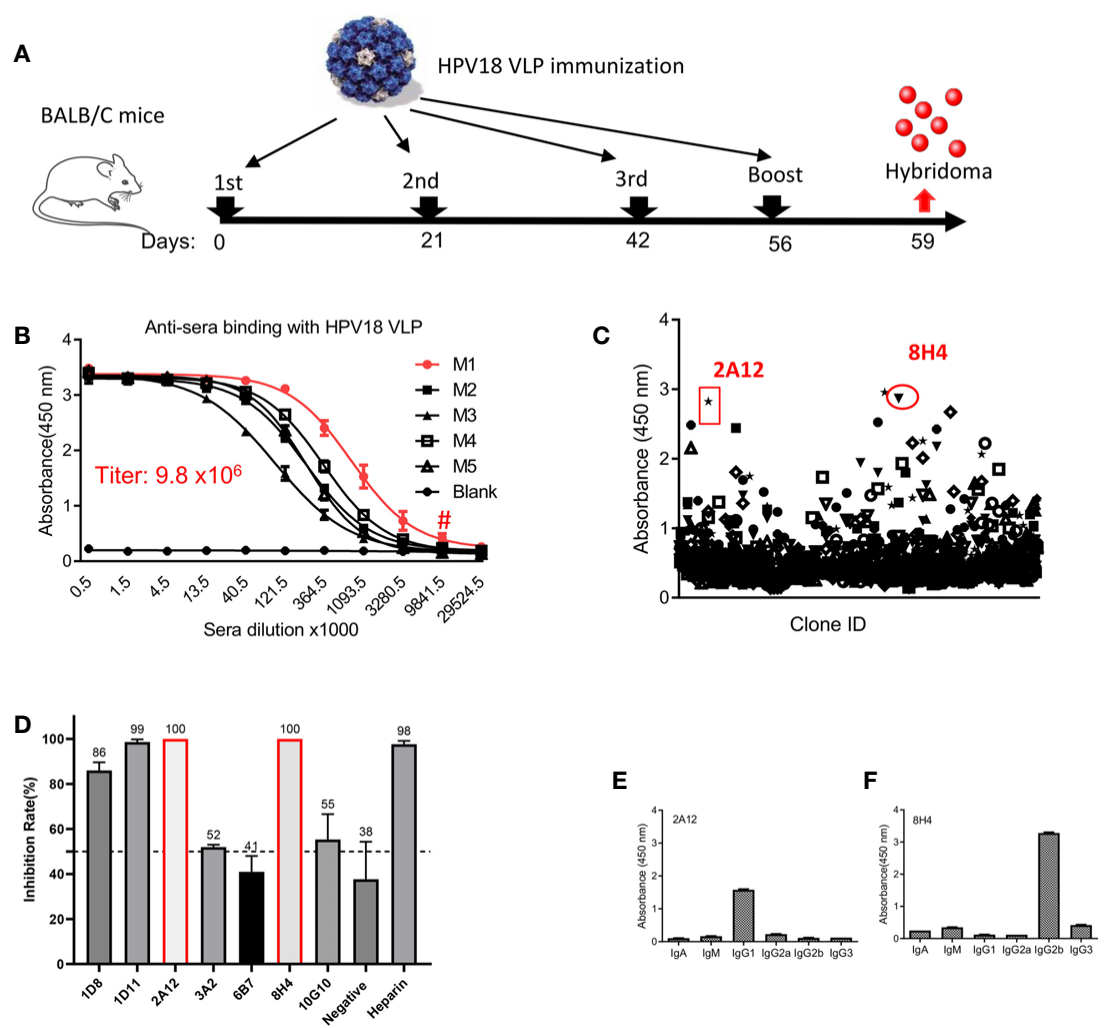

FIGURE 1 | Generation of mAbs against HPV18. (A) The experimental schedule of immunization. (B) The titer of anti-sera was evaluated after the 3rd immunization in mice receiving HPV18 VLP. Y-axis represents the absorbance at $450 \mathrm{~nm}$, and X-axis is the anti-sera dilution fold. Anti-sera from five immunized mice labeled with M1-5 were tested, and serum from non-immunized mice (Blank) were taken as a negative control. M1 presents the best binding (red line), a titer of $9.8 \times 10^{6}$ dilution as indicated by \#. (C) The summary of hybridoma supernatant binding with HPV18 VLP astested by ELISA. Each dot represents the binding of the supernatant from one culture well containing at least one hybridoma. Two dots, shown by red circle, indicate the parental clones of $2 \mathrm{~A} 12$ and $8 \mathrm{H} 14$, respectively. (D) Top seven binders in (C) inhibiting HPV infection, each dot represents one hybridoma supernatant. Cell supernatant and heparin were taken as negative and positive controls, respectively. Two clones present complete inhibition were highlighted with red frame line. Subtype of $2 \mathrm{~A} 12$ (E) and $8 \mathrm{H} 4 \mathbf{( F )}$ was tested by Subtype identification kit. Data of $\mathbf{( B ,} \mathbf{D}-\mathbf{F})$ represent mean \pm SEM. All experiments of $\mathbf{( B - F )}$ were repeated twice.

(Figure 1D), and were selected for further characterization. 2A12 and $8 \mathrm{H} 4$ belong to IgG1 and IgG2b subtypes, respectively, as characterized by a subtyping kit (Figures 1E, F). Overall, Two mAbs with complete inhibition of HPV18 infection were isolated.

\section{Binding Characterization of Downselected Antibodies}

To further characterize the selected monoclonal antibodies, purified $2 \mathrm{~A} 12$ and $8 \mathrm{H} 4$ were prepared and verified by SDSPAGE (Figure 2A). ELISA results showed that $2 \mathrm{~A} 12$ and $8 \mathrm{H} 4$ exhibited high binding with HPV18 VLP with $\mathrm{EC}_{50}$ values of 357 and $100 \mathrm{pM}$, respectively (Figure 2B). The binding of $2 \mathrm{~A} 12$ and $8 \mathrm{H} 4$ to whole VLP was investigated by immune-electronic microscopy (Immune-EM). Dark dots of $10 \mathrm{~nm}$ colloidal gold particles conjugated with $2 \mathrm{~A} 12$ or $8 \mathrm{H} 4$ but not the murine antibody (isotype control) surrounded the outer region of VLP, indicating that $2 \mathrm{~A} 12$ and $8 \mathrm{H} 4$ recognized the HPV18 VLP (Figure 2C). 2A12 and 8H4 showed no reactivity with reduced HPV18 VLP as detected by Western-Blot (Supplemental Figure 1), suggesting that $2 \mathrm{~A} 12$ and $8 \mathrm{H} 4$ epitopes are highly structure dependent. 2A12 and 8H4 were next evaluated for epitope specificity by bio-layer interferometry (BLI) using HPV18 VLP proteins as capture antigens. The antigens captured on AR2G biosensors were bound saturate concentrations $(20 \mu \mathrm{g} / \mathrm{ml})$ of $8 \mathrm{H} 4$ that were followed by $2 \mathrm{~A} 12$ as the competing antibody at a concentration of $20 \mu \mathrm{g} / \mathrm{ml}$. Only antibodies that bind to a non-competing site would be detected in the assay. The results revealed that $2 \mathrm{~A} 12$ could still bind HPV 18 VLP even when HPV18 VLP was saturated by $8 \mathrm{H} 4$, suggesting that $2 \mathrm{~A} 12$ and $8 \mathrm{H} 4$ react with distinct epitopes (Figure 2D). Purified 2A12 and 8H4 were further analyzed for HPV18 VLP binding kinetics by BLI. 2A12 and 8H4 bound HPV18 VLP with $\mathrm{K}_{\mathrm{D}}$ values of 2.14 and $1.68 \mathrm{nM}$, respectively (Figures 2E, F). In summary, $2 \mathrm{~A} 12$ and $8 \mathrm{H} 4$ recognize quaternary and non-overlapping epitopes with high affinity.

\section{Binding Specificity of $2 \mathrm{~A} 12$ and $8 \mathrm{H} 4$ With HPV VLPS}

The cross-reactivity of $2 \mathrm{~A} 12$ and $8 \mathrm{H} 4$ against VLPs from nine common types of HPV, including HPV6, 11, 16, 18, 31, 33, 45, 

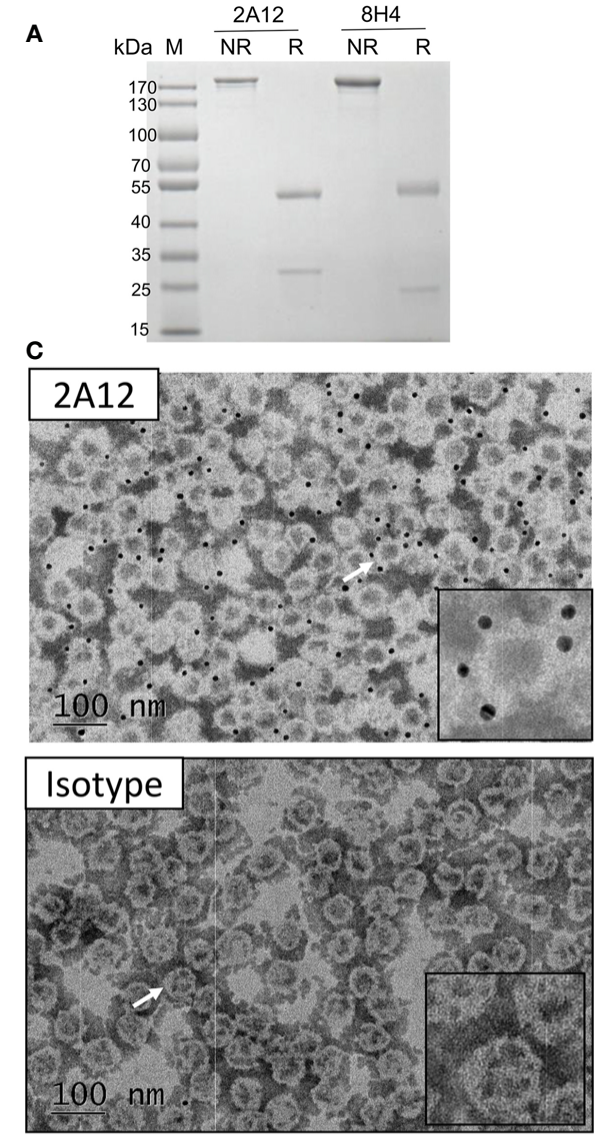

E

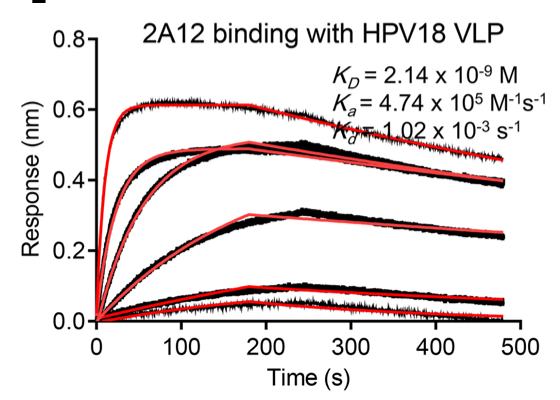

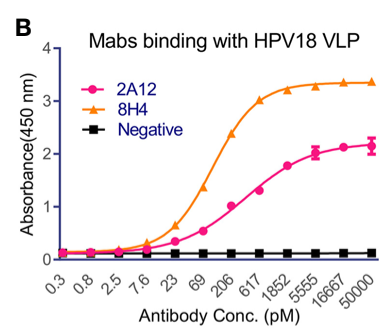

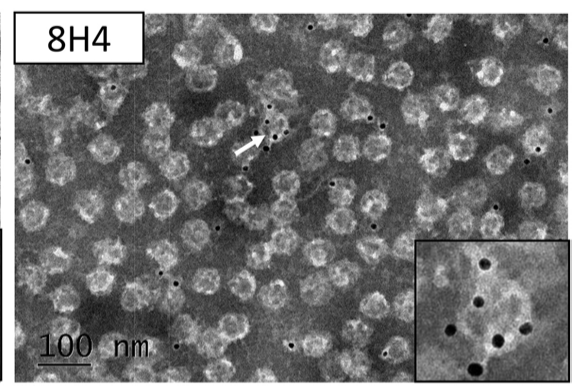

D

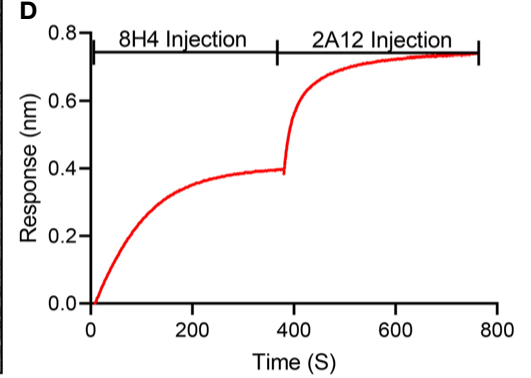

F

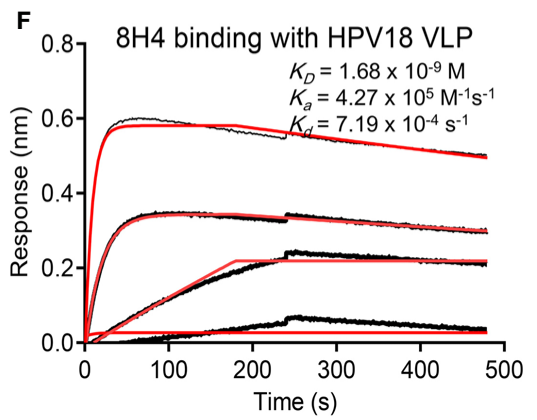

FIGURE 2 | Characterization of 2A12 and 8H14. (A) The purity of 2A12 and 8H4 was determined by SDS-PAGE under non-reducing (NR) or reducing condition (R). (B) Serially diluted 2A12 and 8H4 monoclonal antibody binding with HPV18 VLP was analyzed by ELISA. Data represent mean \pm SEM. (C) Immune electronic microscopy negative staining image showing HPV 18 VLPs recognized by 2A12, $8 \mathrm{H} 4$ and isotype control as indicated. The insets are enlarged images of individual VLP as indicated by corresponding arrows. Black dots are antibody conjugated with $10 \mathrm{~nm}$ colloidal gold particles. Gray circles with the white ring are the VLPs. The bar indicates $100 \mathrm{~nm}$. (D) Epitope specificity analysis of 8H4 and 2A12 by BLI. HPV18 VLP was coated on the sensor, 8H4 antibody was added to bind for 400 s, followed by the addition of 2A12 for another 400 s. Kinetic binding curve of 2A12 (E) and 8H4 (F) with HPV18 VLP. Binding curves are colored black, and fit of the data to a 1:1 binding model is colored red. All experiments were repeated twice.

52 , and 58 was examined by ELISA, cell immunofluorescence and flow cytometry. ELISA showed that $2 \mathrm{~A} 12$ and $8 \mathrm{H} 4$ reacted only with HPV18 VLP (Figure 3A). The specific binding was further validated by cell immunofluorescence and flow cytometry (Figures 3B, C). Altogether, these results indicate that $2 \mathrm{~A} 12$ and $8 \mathrm{H} 4$ recognize respective epitopes that only present on HPV18 VLP.

\section{A12 and 8H4 Exhibited Excellent Neutralizing Potency Against HPV18}

To examine the neutralizing activity of $2 \mathrm{~A} 12$ and $8 \mathrm{H} 4, \mathrm{HPV}$ pseudovirus neutralization experiments were performed. 2A12 and $8 \mathrm{H} 4$ were able to completely neutralize HPV18 infection with high potency at $\mathrm{IC}_{50}$ of 0.44 and $0.86 \mathrm{ng} / \mathrm{ml}$, respectively 
A

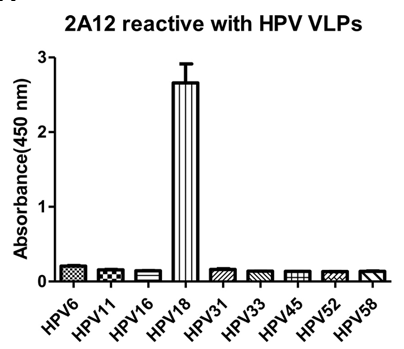

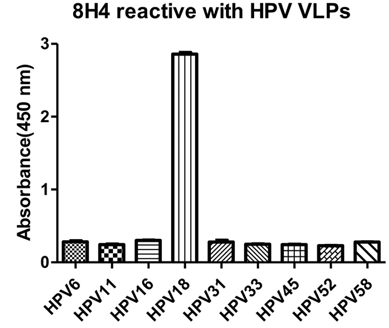

c

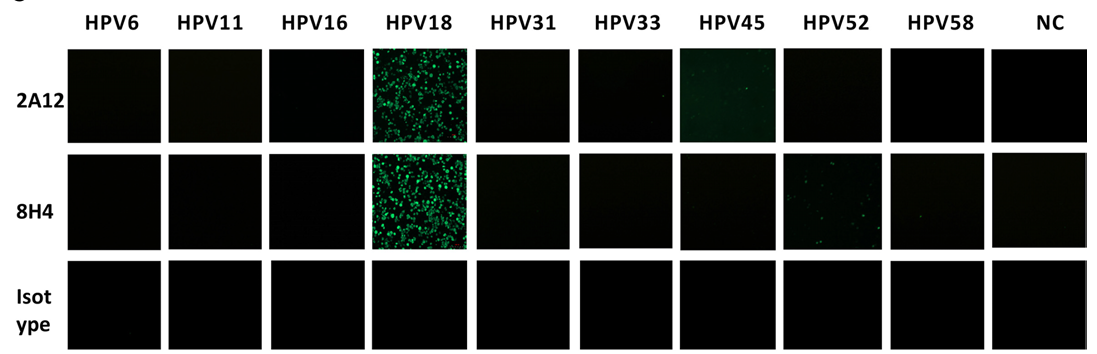

D
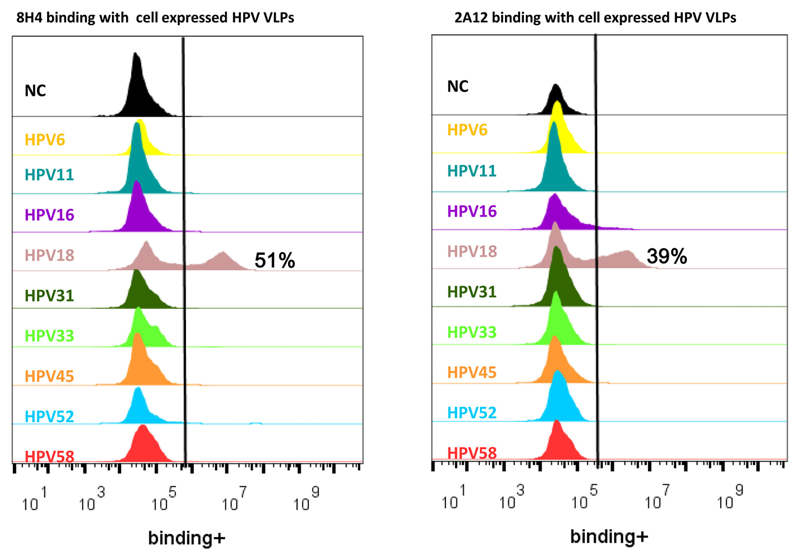

FIGURE 3 | Characterization of binding specificity of 2A12 and 8H4. Analysis of 2A12 (A) and 8H4 (B) binding with VLPs derived from various subtypes of HPV by ELISA. Data represent mean \pm SEM. (C) $2 \mathrm{~A} 12$ and $8 \mathrm{H} 4$ binding with various subtypes of HPV VLPs detected by immunofluorescence assay. Isotype control antibody (Isotype) was taken as a negative control. (D) $2 \mathrm{~A} 12$ and $8 \mathrm{H} 4$ binding with various subtypes HPV VLPs detected by FACS. All experiments were repeated twice.

(Figures 4A, B). Expectedly, 2A12 and 8H4 failed to neutralize the infection of any other eight common HPV subtypes (Figures 4C, D), consistent with their binding specificities (Figure 3). Heparin (H4784, Sigma-Aldrich), a drug used in the treatment of HPV infection (31), was used as the positive control with an $\mathrm{IC}_{50}$ of heparin at $1.82 \times 10^{5} \mathrm{ng} / \mathrm{ml}$. In other words, compared to the heparin control, $2 \mathrm{~A} 12$ and $8 \mathrm{H} 4$ exhibited at least five orders of magnitude more potent neutralizing activity against HPV18 infection.

\section{Functional Activity of Humanized 2A12}

Given that 2A12 exhibited more potent neutralization against HPV18 infection with $\mathrm{IC}_{90}$ of $2.63 \mathrm{ng} / \mathrm{ml}$ compared to that conferred by $8 \mathrm{H} 4$ with $\mathrm{IC}_{90}$ of $35.78 \mathrm{ng} / \mathrm{ml}$ (Figures $4 \mathrm{~A}, \mathbf{B}$ ). As a murine antibody, $2 \mathrm{~A} 12$ will pose potential risk of immunogenicity when applied in human use and, therefore, needs to be humanized for clinical development. Surprisingly, humanized 2A12 (Hu2A12) exhibited improved binding with HPV18 VLP with an $\mathrm{EC}_{50}$ of 74.92 vs $492 \mathrm{pM}$ for the parental 2A12 (Figure 5A). Consistently, Hu2A12 exhibited improved neutralization activity against HPV18 with an $\mathrm{IC}_{50}$ of $0.11 \mathrm{ng} / \mathrm{ml}$ as compared to $2 \mathrm{~A} 12$ with an $\mathrm{IC}_{50}$ of $0.44 \mathrm{ng} / \mathrm{ml}$ (Figure 5B). The improved binding and neutralization activity were substantiated by the increased affinity of Hu2A12 to HPV18 VLP, with the $K_{D}$ of $0.95 \mathrm{nM}$ vs. $2.1 \mathrm{nM}$ for $2 \mathrm{~A} 12$ (Figures 2D, 5C). Together, these results indicate that Hu2A12 has higher affinity and improved neutralization potency than the parental antibody (Figures 5B). 


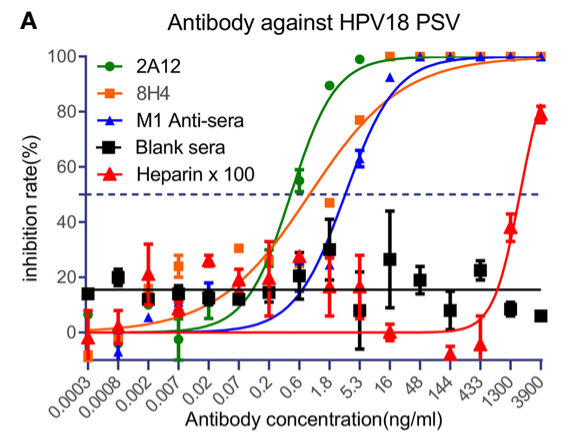

\begin{tabular}{l|c|c|c}
\hline \multicolumn{1}{l|}{ Reagents } & $\begin{array}{c}\mathbf{I C}_{\mathbf{5 0}} \\
(\mathbf{n g} / \mathbf{m l})\end{array}$ & $\begin{array}{c}\mathbf{I C}_{\mathbf{8 0}} \\
(\mathbf{n g} / \mathbf{m l})\end{array}$ & $\begin{array}{c}\mathbf{I C}_{\mathbf{9 0}} \\
(\mathbf{n g} / \mathbf{m l})\end{array}$ \\
\hline $2 \mathrm{~A} 12$ & 0.44 & 1.35 & 2.63 \\
\hline 8H4 & 0.86 & 9.05 & 35.78 \\
\hline M1 Anti-sera & 3.16 & 11.31 & 23.85 \\
\hline Blank sera & $/$ & $/$ & $/$ \\
\hline Heparin & $1.82 \mathrm{E}+05$ & $3.59 \mathrm{E}+05$ & $/$ \\
\hline
\end{tabular}
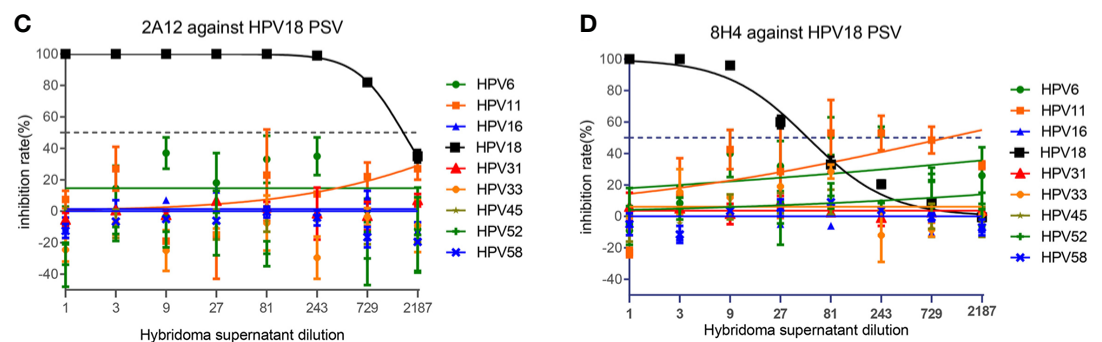

FIGURE 4 | Neutralization activity of 2A12 and 8H4. (A) Neutralization activity of mAbs and mouse sera against HPV18 pseudovirus infection. Heparin was taken as a positive control and heparin $\times 100$ represents that the concentration of heparin in use is the indicated concentration at $X$ axis multiply 100 fold. (B) Summary of the neutralization titers $\left(\mathrm{IC}_{50}, \mathrm{IC}_{80}\right.$ and $\left.\mathrm{IC}_{90}\right)$ against HPV18 pseudovirus infection. Neutralization activity of $2 \mathrm{~A} 12$ (C) and $8 \mathrm{H} 4$ (D) against the pseudovirus infection of various HPV subtypes. Data represent mean \pm SEM. All experiments were repeated twice.

Given the fact that vaginal environment is acidic and HPV neutralizing antibodies topically applied must sustain the degradation, the potency of Hu2A12 against HPV18 in various acidic $\mathrm{pH}$ settings was evaluated. $\mathrm{IC}_{50}$ values in $\mathrm{pH} 4.0,5.0,6.0$ and 7.0 were $0.77,0.134,0.08$ and $0.04 \mathrm{ng} / \mathrm{ml}$, respectively (Figures 5D, E), showing the decreasing trend as the $\mathrm{pH}$ dropped though still highly potent with an $\mathrm{IC}_{50}$ of $0.77 \mathrm{ng} / \mathrm{ml}$ at $\mathrm{pH} 4.0$ (Figures 5D, E). Given the $\mathrm{pH}$ values ranged from $\mathrm{pH}$ 4.0 to 6.0 in the vaginal cervix (32), such acidic environment may have a limited impact on the neutralizing activity of Hu2A12. Together, these data indicates that $\mathrm{Hu} 2 \mathrm{~A} 12$ could retain neutralizing activity as a topical agent for the treatment of HPV cervical infection.

\section{In Vitro and In Vivo Characterization of Hu2A12-Hydrogel Formulation}

$\mathrm{Hu} 2 \mathrm{~A} 12$ was formulated in hydrogel as a topical agent to increase vaginal retention and improve release. Hu2A12 in the hydrogel was completely released within 48 hours and the released $\mathrm{Hu} 2 \mathrm{~A} 12$ retained comparable neutralizing activity, indicating that Hu2A12-hydrogel could be applied to treat HPV 18 infection as vaginal biopharmaceutical agent (Figures 6A, B). To measure the kinetics of Hu2A12 in the form of hydrogel, hydrogel containing $2 \mathrm{~A} 12$ was applied to mouse vaginal and the release of $\mathrm{Hu} 2 \mathrm{~A} 12$ was monitored at various time points. $\mathrm{Hu} 2 \mathrm{~A} 12$ could be observed in mouse vaginal within $48 \mathrm{~h}$ (Figures 6C, D), consistent with the released results of in vitro experiment as shown in Figure 6A. H\&E-stained vaginal tissues of the above mice showed that Hu2A12 in hydrogel did not induce infiltration of inflammatory cells in the vaginal sections compared to the Mock control (Figure 6E), suggesting that Hu2A12 in hydrogel induced no toxic to vaginal tissue as topical agents. Altogether, Hu2A12-hydrogel could be released and retained anti-viral activity against HPV infection in the vaginal cervix.

\section{DISCUSSION}

Current prophylactic HPV vaccines have achieved significant prevention against HPV infection. However, a large number of women still fail to receive prophylactic HPV vaccines due to various reasons, such as costs, availability, or nonresponding to vaccination. In 2018, there were 570,000 reported new cases and 311,000 related deaths, suggesting that effective medical treatment of HPV infection is urgently needed.

Persistent HPV infection is the main risk factor and a prerequisite for the development of the premalignant conditions of cervical intraepithelial neoplasia or adenocarcinoma in situ. Therefore, neutralizing antibodies can be used to block the released virus from infecting nascent epithelial cells, thus inhibiting the malignant transformation of the cells. Neutralizing antibodies have been widely applied to treat viral infections caused by RSV, Ebola, HIV, SAR-CoV-2 etc. However, the development of HPV neutralizing antibodies is very rare. 


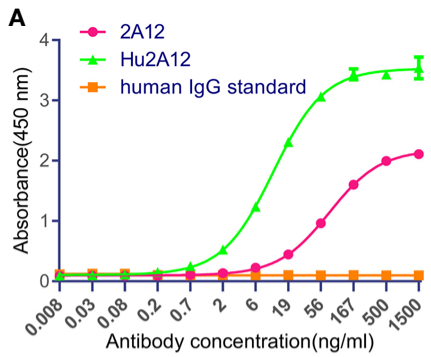

\section{C}

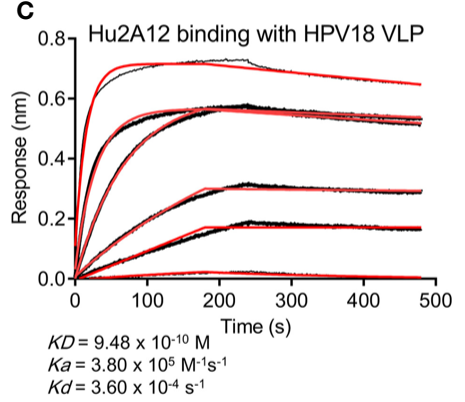

B

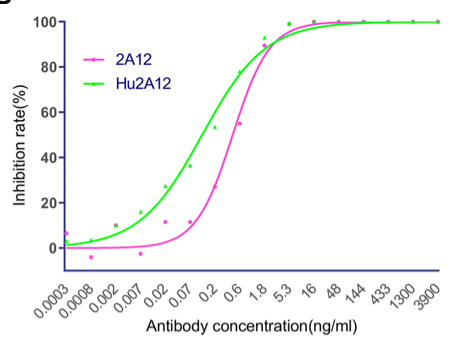

D

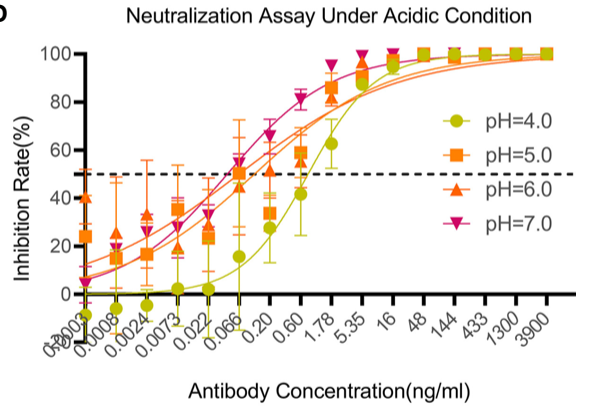

E

\begin{tabular}{c|c|c|c}
\hline $\mathbf{p H}$ Values & $\begin{array}{c}\mathbf{I C}_{\mathbf{5 0}} \\
(\mathbf{n g} / \mathbf{m l})\end{array}$ & $\begin{array}{c}\mathbf{I C}_{\mathbf{8 0}} \\
(\mathbf{n g} / \mathbf{m l})\end{array}$ & $\begin{array}{c}\mathbf{I C}_{\mathbf{9 0}} \\
(\mathbf{n g} / \mathbf{m l})\end{array}$ \\
\hline 7 & 0.0432 & 0.5582 & 2.5 \\
\hline 6 & 0.087 & 2.615 & 19.13 \\
\hline 5 & 0.1347 & 2.556 & 14.29 \\
\hline 4 & 0.7732 & 3.998 & 10.45 \\
\hline
\end{tabular}

FIGURE 5 | Characterization of humanized 2A12. (A) ELISA analysis of the reactivity of 2A12 and humanized 2A12 (Hu2A12) with HPV18 VLP. PBS binding with sGn served as a control (Blank). Data represent mean \pm SEM (B) Neutralization activity of Hu2A12 against HPV18 pseudovirus infection. Data represent mean \pm SEM. (C) Kinetic binding curve of Hu2A12 with HPV18 VLP. Binding curves are colored black, and fit of the data to a 1:1 binding model is colored red.

(D) Neutralization activity of Hu2A12 against HPV18 pseudovirus infection under various $\mathrm{pH}$. Different color curves represent different pH. (E) The summary of the neutralization titers $\left(\mathrm{IC}_{50}, \mathrm{IC}_{80}\right.$ and $\left.\mathrm{IC}_{90}\right)$ against HPV18 pseudovirus infection in (D). Data represent mean \pm SEM. All experiments were repeated twice.

Thus our potent neutralizing antibody, $\mathrm{Hu} 2 \mathrm{~A} 12$, will be a potential candidate therapeutic agent for the topical treatment of HPV18 infection.

Considering the repeated cycles of HPV release and infection in the cervical basal epithelium, topical application of neutralizing antibodies will be a plausible approach to stop the $\mathrm{HPV}$ infection, thus preventing malignant transformation of the epithelium. Acid stable Hu2A12 will offer a valuable advantage for its application at the vaginal/cervical environment. In addition, the slow-release and the retention of bioactivity of Hu2A12 in hydrogel formulation offer additional benefits for using the antibody as a topical agent to treat HPV18 infection. Unlike vaccines, which usually take weeks to generate immune protection in vaccinated individuals, neutralizing $\mathrm{mAbs}$ as topical agents may provide immediate protection against viral infection, and are thus suitable for people at all ages and particularly suitable for high-risk populations and immunocompromised individuals who typically do not generate sufficient nAbs after vaccination. Furthermore, topical agents could release high concentration of potent neutralizing mAbs at the HPV infected sites compared to the systemic neutralizing mAbs elicited by HPV vaccine. In the developing world, even if the vaccines are available it would take many years to build up enough coverage of the populations under risk; therefore, in the foreseeable future women will continue to be infected and effective treatment drugs will be needed. Altogether, compared to the success in the prevention of HPV infection achieved by current licensed HPV vaccines, topical hydrogels containing anti-viral agents may provide immediate treatment for people without receiving HPV vaccines or who fail to mount antibody immunity after vaccination.

In this study, two potent neutralizing antibodies, 2A12 and $8 \mathrm{H} 4$ were isolated from hybridomas prepared from the mice immunized with HPV 18 VLP. Both $2 \mathrm{~A} 12$ and $8 \mathrm{H} 4$ could completely neutralize HPV18 infection with high potency with $\mathrm{IC}_{50}$ values of 0.44 to $0.86 \mathrm{ng} / \mathrm{ml}$ (Figures $4 \mathbf{A}, \mathbf{B}$ ). To our knowledge, these two antibodies are the most potent mAbs against HPV18 reported. Furthermore, 2A12 and 8H4 recognize 

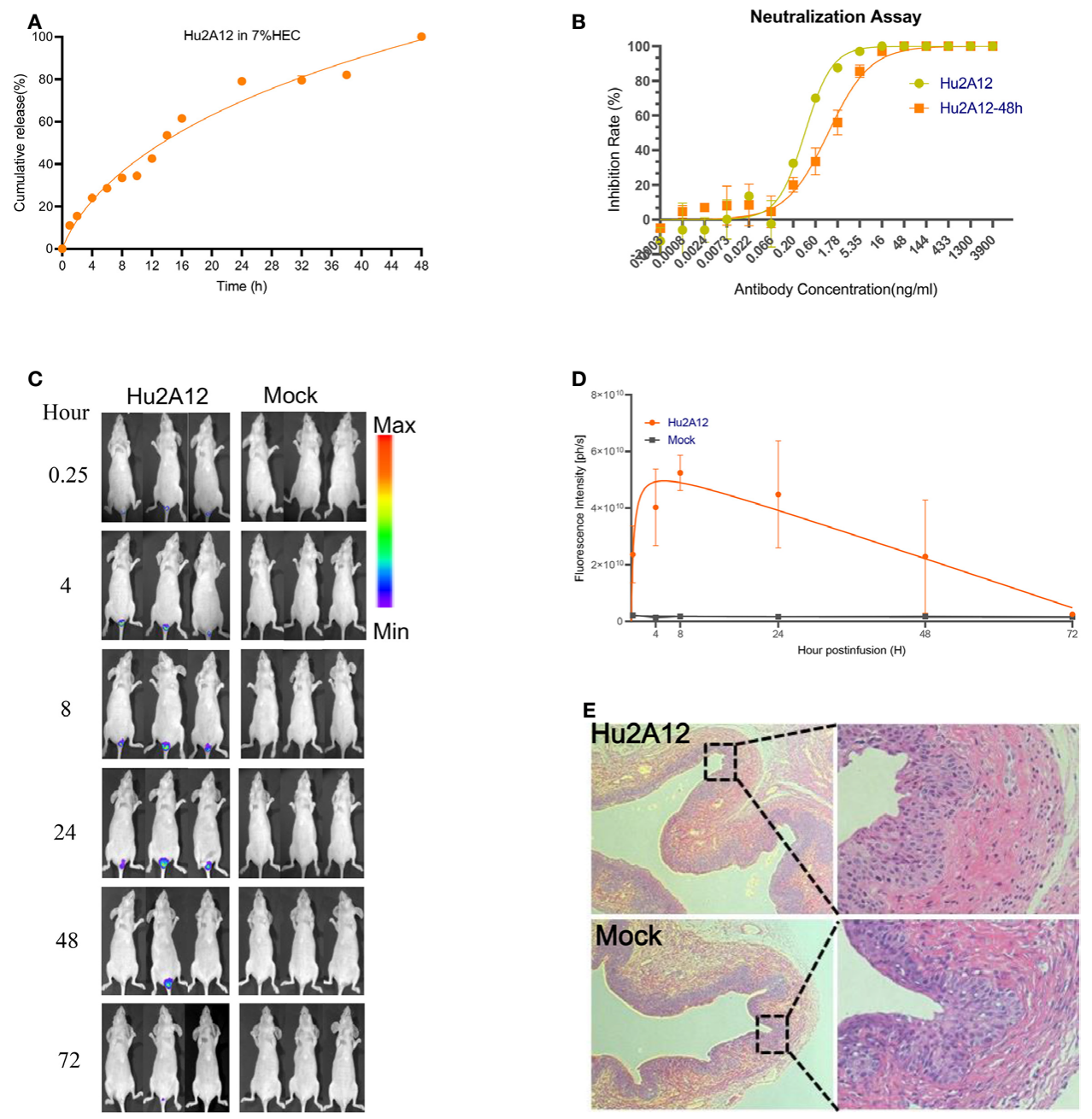

FIGURE 6 | Characterization of Hu2A12 in gel. (A) The release of Hu2A12 in gel was determined at the indicated time. Data represent mean \pm SEM.

(B) Neutralization activity of Hu2A12 and Hu2A12 released from the gel at $48 \mathrm{~h}$ (Hu2A12-48h). Data represent mean \pm SEM. (C) Sequential in vivo imaging of Hu2A12-750 conjugated with dye YF750 injected into the vagina of nude mice. (D). Fluorescence intensity (ph/s) of mice shown in (C). Data represent mean \pm SEM. (E) Representative vaginal sections of mice from Hu2A12 in hydrogel and Mock group in (B) were analyzed by H\&E staining. The right panel is enlarged images as indicated by rectangle.Images were visualized under $\times 10$ objective lens. All experiments of (B, D, E) were repeated twice.

distinct quaternary epitopes and exhibit highly specific binding with HPV18. Hu2A12 exhibited improved neutralizing activity against HPV18 infection and its neutralization activity was not affected in various acidic $\mathrm{pH}$ settings and in hydrogel (Figures 5D, E), suggesting that $\mathrm{Hu} 2 \mathrm{~A} 12$ can be a promising candidate for topical therapeutic agent against HPV18 infection.

Several topical therapies for HPV or CIN, including immunemodulators, anti-proliferative medications, antivirals, hormones, and herbal/alternative therapies are in various stages of clinical trial (11). Nevertheless, studies of antibodies as topical agents against HPV have been limited due to the difficulty in isolating antibodies with potent neutralizing activities, the challenge in delivering antibodies to the infection sites in the basal layer of the cervical epithelium and the efficacy of antibodies eliminating infected cells. The development of Hu2A12 will open a new therapeutic avenue for neutralizing antibodies as topical agents in treating other high-risk HPV infections such as HPV16, 31, 33, 45, 52, 58 etc.

The main limitation of this study is not evaluating the in vivo efficacy of Hu2A12-hydrogel in the treatment of HPV 18 infection due to the lack of a suitable small animal model. Clinical trials demonstrated that robust neutralizing antibodies against HPV in serum and in cervicovaginal secretions were correlated to protection $(33,34)$, suggesting that human studies in the evaluating Hu2A12 as topical agents will be merited.

In summary, Hu2A12 with high neutralization potency against HPV18 was developed. The efficacy, delivery, safety, and accessibility of Hu2A12 were characterized, indicating that $\mathrm{Hu} 2 \mathrm{~A} 12$ will be promising as a topical agent to treat HPV18 infection. 


\section{DATA AVAILABILITY STATEMENT}

The raw data supporting the conclusions of this article will be made available by the authors, without undue reservation.

\section{ETHICS STATEMENT}

The animal study was reviewed and approved by the Committee on the Use of Live Animals by the Ethics Committee of Nanjing Drum Tower Hospital.

\section{AUTHOR CONTRIBUTIONS}

All authors contributed to the work fulfilled the criteria adopted from ICMJE. BH, LZ, and XW conducted most experiments, analyzed the data, and wrote the draft manuscript. HW, HS, DZ, $\mathrm{HY}, \mathrm{NZ}, \mathrm{SX}, \mathrm{WN}$, and YH provided technical assistance and did animal experiments. XW and ZW designed the study, monitored and financially supported the study, and revised the manuscript.

\section{REFERENCES}

1. Small W Jr, Bacon MA, Bajaj A, Chuang LT, Fisher BJ, Harkenrider MM, et al. Cervical Cancer: A Global Health Crisis. Cancer (2017) 123(13):2404-12. doi: $10.1002 / \mathrm{cncr} .30667$

2. Doorbar J, Quint W, Banks L, Bravo IG, Stoler M, Broker TR, et al. The Biology and Life-Cycle of Human Papillomaviruses. Vaccine (2012) 30:F5570. doi: 10.1016/j.vaccine.2012.06.083

3. Woodman CBJ, Collins SI, Young LS. The Natural History of Cervical HPV Infection: Unresolved Issues. Nat Rev Cancer (2007) 7(1):11-22. doi: 10.1038/ nrc2050

4. Harper DM, DeMars LR. HPV Vaccines - A Review of the First Decade. Gynecologic Oncol (2017) 146(1):196-204. doi: 10.1016/j.ygyno.2017.04.004

5. Castle PE, Maza M. Prophylactic HPV Vaccination: Past, Present, and Future. Epidemiol Infect (2016) 144(3):449-68. doi: 10.1017/S09502 68815002198

6. Arbyn M, Weiderpass E, Bruni L, de Sanjose S, Saraiya M, Ferlay J, et al. Estimates of Incidence and Mortality of Cervical Cancer in 2018: A Worldwide Analysis. Lancet Glob Health (2020) 8(2):E191-203. doi: 10. 1016/S2214-109X(19)30482-6

7. Dadar M, Chakraborty S, Dhama K, Prasad M, Khandia R, Hassan S, et al. Advances in Designing and Developing Vaccines, Drugs and Therapeutic Approaches to Counter Human Papilloma Virus. Front Immunol (2018) 9:2478. doi: 10.3389/fimmu.2018.02478

8. Grimm C, Polterauer S, Natter C, Rahhal J, Hefler L, Tempfer CB, et al. Treatment of Cervical Intraepithelial Neoplasia With Topical Imiquimod a Randomized Controlled Trial. Obstet Gynecol (2012) 120(1):152-9. doi: 10.1097/AOG.0b013e31825bc6e8

9. Maiman M, Watts DH, Andersen J, Clax P, Merino M, Kendall MA. Vaginal 5-Fluorouracil for High-Grade Cervical Dysplasia in Human Immunodeficiency Virus Infection: A Randomized Trial. Obstet Gynecol (1999) 94(6):954-61. doi: 10.1016/S0029-7844(99)00407-X

10. Snoeck R, Noel JC, Muller C, De Clercq E, Bossens M. Cidofovir, a New Approach for the Treatment of Cervix Intraepithelial Neoplasia Grade III (CIN III). J Med Virol (2000) 60(2):205-9. doi: 10.1002/(SICI)1096-9071 (200002)60:2<205::AID-JMV16>3.0.CO;2-8

11. Desravines N, Miele K, Carlson R, Chibwesha C, Rahangdale L. Topical Therapies for the Treatment of Cervical Intraepithelial Neoplasia (CIN) 2-3:
All authors contributed to the article and approved the submitted version.

\section{FUNDING}

This work was supported by The Major Research and Development Project (2018ZX10301406 to ZW), National Science Foundation of China (NSFC) (No. 81803414 to XW, 31970149 to ZW), Nanjing University-Ninxia University Collaborative Project (Grant\# 2017BN04 to ZW), Research Foundation of JiangSu Commission Health project (Grant\# ZDA2020014 to XW), and Jiangsu province "Innovative and Entrepreneurial talent" and Six Talent Peaks Project of Jiangsu Province.

\section{SUPPLEMENTARY MATERIAL}

The Supplementary Material for this article can be found online at: https://www.frontiersin.org/articles/10.3389/fimmu.2021. 678318/full\#supplementary-material

A Narrative Review. Gynecologic Oncol Rep (2020) 33:100608. doi: 10.1016/ j.gore.2020.100608

12. Stern PL, van der Burg SH, Hampson IN, Broker TR, Fiander A, Lacey CJ, et al. Therapy of Human Papillomavirus-Related Disease. Vaccine (2012) 30 (Suppl 5):F71-82. doi: 10.1016/j.vaccine.2012.05.091

13. Walker LM, Burton DR. Passive Immunotherapy of Viral Infections: 'SuperAntibodies' Enter the Fray. Nat Rev Immunol (2018) 18(5):297-308. doi: $10.1038 /$ nri.2017.148

14. Kaplon H, Muralidharan M, Schneider Z, Reichert JM. Antibodies to Watch in 2020. MAbs (2020) 12(1):1703531. doi: 10.1080/19420862.2019. 1703531

15. Guan P, Clifford GM, Franceschi S. Human Papillomavirus Types in Glandular Lesions of the Cervix: A Meta-Analysis of Published Studies. Int J Cancer (2013) 132(1):248-50. doi: 10.1002/ijc.27663

16. Li N, Franceschi S, Howell-Jones R, Snijders PJ, Clifford GM. Human Papillomavirus Type Distribution in 30,848 Invasive Cervical Cancers Worldwide: Variation by Geographical Region, Histological Type and Year of Publication. Int J Cancer (2011) 128(4):927-35. doi: 10.1002/ ijc. 25396

17. Gagliardi A, Porter VL, Zong Z, Bowlby R, Titmuss E, Namirembe C, et al. Analysis of Ugandan Cervical Carcinomas Identifies Human Papillomavirus Clade-Specific Epigenome and Transcriptome Landscapes. Nat Genet (2020) 52(8):800-10. doi: 10.1038/s41588-020-0673-7

18. Rader JS, Tsaih SW, Fullin D, Murray MW, Iden M, Zimmermann MT, et al. Genetic Variations in Human Papillomavirus and Cervical Cancer Outcomes. Int J Cancer (2019) 144(9):2206-14. doi: 10.1002/ijc.32038

19. Zhang Y, He Y, Li L, Liang ST, Yan M, Ren DY, et al. Development and Characterization of an HPV18 Detection Kit Using Two Novel HPV18 TypeSpecific Monoclonal Antibodies. Diagn Pathol (2018) 13:55. doi: 10.1186/ s13000-018-0727-7

20. Wu X, Ma X, Li Y, Xu Y, Zheng N, Xu S, et al. Induction of Neutralizing Antibodies by Human Papillomavirus Vaccine Generated in Mammalian Cells. Antibody Ther (2019) 2(2):45-53. doi: 10.1093/abt/tbz004

21. Greenfield EA. Electro Cell Fusion for Hybridoma Production. Cold Spring Harb Protoc (2019) 2019(10):684-88. doi: 10.1101/pdb.prot103184

22. Rems L, Usaj M, Kanduser M, Rebersek M, Miklavcic D, Pucihar G. Cell Electrofusion Using Nanosecond Electric Pulses. Sci Rep (2013) 3:3382. doi: $10.1038 /$ srep03382 
23. Buck CB, Pastrana DV, Lowy DR, Schiller JT. Generation of HPV Pseudovirions Using Transfection and Their Use in Neutralization Assays. Methods Mol Med (2005) 119:445-62. doi: 10.1385/1-59259982-6:445

24. Guo X, Zhang L, Zhang W, Chi Y, Zeng X, Li X, et al. Human Antibody Neutralizes Severe Fever With Thrombocytopenia Syndrome Virus, an Emerging Hemorrhagic Fever Virus. Clin Vaccine Immunol (2013) 20 (9):1426-32. doi: 10.1128/CVI.00222-13

25. Johnston CM, Wood AL, Bolland DJ, Corcoran AE. Complete Sequence Assembly and Characterization of the C57BL/6 Mouse Ig Heavy Chain V Region. J Immunol (2006) 176(7):4221-34. doi: 10.4049/ jimmunol.176.7.4221

26. Safdari Y, Farajnia S, Asgharzadeh M, Khalili M. Antibody Humanization Methods - A Review and Update. Biotechnol Genet Eng Rev (2013) 29:175-86. doi: 10.1080/02648725.2013.801235

27. Ahmadzadeh V, Farajnia S, Feizi MA, Nejad RA. Antibody Humanization Methods for Development of Therapeutic Applications. Monoclon Antib Immunodiagn Immunother (2014) 33(2):67-73. doi: 10.1089/mab.2013.0080

28. Zhai J, Mantaj J, Vllasaliu D. Ascorbyl Palmitate Hydrogel for Local, Intestinal Delivery of Macromolecules. Pharmaceutics (2018) 10(4):188. doi: 10.3390/ pharmaceutics 10040188

29. Aprodu A, Mantaj J, Raimi-Abraham B, Vllasaliu D. Evaluation of a Methylcellulose and Hyaluronic Acid Hydrogel as a Vehicle for Rectal Delivery of Biologics. Pharmaceutics (2019) 11(3):127. doi: 10.3390/pharmaceutics11030127

30. Epstein-Barash H, Stefanescu CF, Kohane DS. An in Situ Cross-Linking Hybrid Hydrogel for Controlled Release of Proteins. Acta Biomater (2012) 8 (5):1703-9. doi: 10.1016/j.actbio.2012.01.028

31. Giroglou T, Florin L, Schafer F, Streeck RE, Sapp M. Human Papillomavirus Infection Requires Cell Surface Heparan Sulfate. J Virol (2001) 75(3):1565-70. doi: 10.1128/JVI.75.3.1565-1570.2001
32. Laniewski P, Cui HY, Roe DJ, Barnes D, Goulder A, Monk BJ, et al. Features of the Cervicovaginal Microenvironment Drive Cancer Biomarker Signatures in Patients Across Cervical Carcinogenesis. Sci Rep (2019) 9:7333. doi: 10.1038/ s41598-019-43849-5

33. Zhao H, Lin Z-J, Huang S-J, Li J, Liu X-H, Guo M, et al. Correlation Between ELISA and Pseudovirion-Based Neutralisation Assay for Detecting Antibodies Against Human Papillomavirus Acquired by Natural Infection or by Vaccination. Hum Vaccines Immunotherapeutics (2014) 10(3):740-6. doi: 10.4161/hv.27619

34. Huh WK, Joura EA, Giuliano AR, Iversen OE, de Andrade RP, Ault KA, et al. Final Efficacy, Immunogenicity, and Safety Analyses of a Nine-Valent Human Papillomavirus Vaccine in Women Aged 16-26 Years: A Randomised, Double-Blind Trial. Lancet (2017) 390(10108):2143-59. doi: 10.1016/S01406736(17)31821-4

Conflict of Interest: Author LZ was employed by the company Abrev Biotechnology Co., Ltd. Author HS was employed by Y-Clone Medical Science Co. Ltd. A patent application on 2A12 was submitted by Y-Clone Medical science Co. Ltd., under CN201911358261X.

The remaining authors declare that the research was conducted in the absence of any commercial or financial relationships that could be construed as a potential conflict of interest.

Copyright (C) 2021 Huang, Zhu, Wei, Shi, Zhang, Yuan, Luan, Zheng, Xu, Nawaz, Hong, $W u$ and $W u$. This is an open-access article distributed under the terms of the Creative Commons Attribution License (CC BY). The use, distribution or reproduction in other forums is permitted, provided the original author(s) and the copyright owner(s) are credited and that the original publication in this journal is cited, in accordance with accepted academic practice. No use, distribution or reproduction is permitted which does not comply with these terms. 